\title{
Value of combined detection of anti-nuclear antibody, anti-double-stranded DNA antibody and C3, C4 complements in the clinical diagnosis of systemic lupus erythematosus
}

\author{
CHANGHUA QU ${ }^{1 *}$, JUAN ZHANG $^{2 *}$, XIUMEI ZHANG ${ }^{3}$, JIEXIN DU $^{4}$, BAIFANG SU $^{5}$ and HONG $\mathrm{LI}^{6}$ \\ ${ }^{1}$ Department of Clinical Laboratory, Yantaishan Hospital of Yantai; ${ }^{2}$ Outpatient Department, \\ Yantai Yeda Hospital, Yantai, Shandong 264000; Departments of ${ }^{3}$ Internal Medicine and ${ }^{4}$ Neurology, \\ The People's Hospital of Zhangqiu Area; ${ }^{5}$ Department of Science and Education, Jinan Zhangqiu \\ District Hospital of TCM, Zhangqiu, Shandong 250200; ${ }^{6}$ Department of Clinical Laboratory, \\ The Fifth People's Hospital of Jinan, Jinan, Shandong 250022, P.R. China
}

Received May 22, 2018; Accepted November 19, 2018

DOI: $10.3892 /$ etm.2018.7072

\begin{abstract}
Combined detection of antinuclear antibody (ANA), anti-double-stranded DNA (ds-DNA) antibody and complements $\mathrm{C} 3$ and $\mathrm{C} 4$ in the diagnosis of systemic lupus erythematosus (SLE) was analyzed. One hundred and ninety-four patients with SLE admitted to Yantaishan Hospital of Yantai from January 2012 to December 2017 were selected as SLE group. A total of 106 patients with non-SLE rheumatic disease were selected as disease control group and 120 healthy subjects as healthy control group. The ANA and anti-ds-DNA antibodies were detected by ELISA and complement C3 and C4 were detected by rate nephelometry. The sensitivity and specificity of these four factors were also analyzed for the diagnosis of SLE. The sensitivity and specificity of ANA in diagnosing SLE were 91.75 and $79.65 \%$, respectively; of anti-ds-DNA antibody were 67.01 and $98.23 \%$, respectively; of complement C3 were 87.11 and $82.74 \%$, respectively; and of complement $\mathrm{C} 4$ were 88.66 and $77.43 \%$, respectively. The sensitivity and specificity of ANA and anti-ds-DNA antibody in the diagnosis of SLE were 95.36 and $96.90 \%$, respectively; of C3 and C4 were 92.78 and $79.20 \%$, respectively; and the sensitivity and specificity of the combination of all four indicators were 97.42 and $80.97 \%$, respectively. The combined diagnosis of SLE with ANA, anti-ds-DNA antibody, complement C3 and $\mathrm{C} 4$ can play a complementary role in the diagnosis and
\end{abstract}

Correspondence to: Dr Hong Li, Department of Clinical Laboratory, The Fifth People's Hospital of Jinan, 24297 Jingshi Road, Jinan, Shandong 250022, P.R. China

E-mail: nqq5c8@163.com

${ }^{*}$ Contributed equally

Key words: systemic lupus erythematosus, antinuclear antibody, anti-double-stranded DNA antibody, complement C3, complement C4 treatment of SLE patients, and it is of great significance to the diagnosis and treatment planning of SLE patients.

\section{Introduction}

Systemic lupus erythematosus (SLE) is a diffuse connective tissue disease transmitted by autoimmunity as a medium (1), characterized by long duration, easy recurrence, and high mortality. It has not been clearly defined yet and is still incurable (2). The disease occurs in young women of childbearing age and the prevalence of females accounts for $90 \%$ of the total number of affected patients. The peak age of the disease is $15-40$ years $(3,4)$. SLE usually affects the whole body, and there are multiple autoantibodies in the patient's serum as clinical features. The course of SLE, the number of affected organs and the prognosis of survival are negatively correlated (5). These autoantibodies, which are immune complexes, bind to their corresponding antigens to form antigen-antibody complexes which then are deposited in the kidneys, blood vessels, subcutaneous tissue, or even the nervous system, promoting multiple organ and tissue damage (6). Currently, steroids, immunosuppressants and other drugs are used to treat SLE. However, in addition to relieving the disease, many adverse reactions are also caused to the body (7). Therefore, it is of great significance to detect multiple autoantibodies in SLE patients' sera and provide evidence for clinical rational drug use.

The antinuclear antibody (ANA) is a general term for autoantibodies against various nuclear components (8). ANA can be seen in all kinds of rheumatic diseases (9). The currently recognized autoantibody markers for the diagnosis of SLE are anti-double-stranded DNA (ds-DNA) antibodies, because high concentrations of anti-ds-DNA antibodies are almost exclusively present in SLE patients, anti-ds-DNA antibodies are SLE-specific (10). C3 and C4 are important components in the complement system and play an important role in complement activation, participating in immunity and maintaining internal environment stability (11).

The purpose of this study was to detect ANA, anti-ds-DNA antibody, and complement C3, C4 in the serum of 194 patients 
Table I. General information.

\begin{tabular}{|c|c|c|c|c|c|}
\hline Factor & $\begin{array}{l}\text { SLE group } \\
\quad(n=194)\end{array}$ & $\begin{array}{l}\text { Disease control } \\
\text { group }(n=106)\end{array}$ & $\begin{array}{l}\text { Control group } \\
\quad(n=120)\end{array}$ & $\mathrm{F} / \chi^{2}$ & P-value \\
\hline \multicolumn{6}{|l|}{ Age (years) } \\
\hline$\geq 40$ & $72(37.11)$ & $52(49.06)$ & $46(38.33)$ & \multirow[t]{2}{*}{4.378} & \multirow[t]{2}{*}{0.112} \\
\hline$<40$ & $122(62.89)$ & $54(50.94)$ & $74(61.67)$ & & \\
\hline \multicolumn{6}{|l|}{ Sex } \\
\hline Male & $23(11.86)$ & $18(16.98)$ & $20(16.67)$ & \multirow[t]{2}{*}{2.072} & \multirow[t]{2}{*}{0.355} \\
\hline Female & $171(88.14)$ & $88(83.02)$ & $100(83.33)$ & & \\
\hline \multicolumn{6}{|l|}{ Marriage and childbirth } \\
\hline Yes & $161(82.99)$ & $82(77.36)$ & $86(71.67)$ & \multirow[t]{2}{*}{5.680} & \multirow[t]{2}{*}{0.058} \\
\hline No & $33(17.01)$ & $24(22.64)$ & $34(28.33)$ & & \\
\hline Average volume of red blood cells (fl) & $84.65 \pm 3.30$ & $86.72 \pm 3.12$ & $89.68 \pm 0.28$ & 124.90 & $<0.001$ \\
\hline Erythrocyte distribution width (\%) & $15.51 \pm 2.57$ & $13.42 \pm 0.81$ & $12.56 \pm 0.76$ & 106.10 & $<0.001$ \\
\hline Platelets $\left(10^{9} / 1\right)$ & $85.42 \pm 0.73$ & $164.21 \pm 18.94$ & $198.74 \pm 32.21$ & $1,360.00$ & $<0.001$ \\
\hline $\operatorname{Hcy}(\mu \mathrm{mol} / \mathrm{l})$ & $14.31 \pm 2.13$ & $11.25 \pm 2.48$ & $9.15 \pm 2.41$ & 194.9 & $<0.001$ \\
\hline Total cholesterol (mmol/l) & $5.75 \pm 2.45$ & $5.03 \pm 1.05$ & $4.12 \pm 0.85$ & 30.31 & $<0.001$ \\
\hline Urine protein $(\mathrm{g} / 24 \mathrm{~h})$ & $4.13 \pm 3.12$ & $2.21 \pm 1.86$ & $0.05 \pm 0.02$ & 115.7 & $<0.001$ \\
\hline
\end{tabular}

SLE, systemic lupus erythematosus.

with SLE, 106 patients with non-SLE, and 120 healthy volunteers, and to investigate the diagnostic value of these four factors, either alone or in combination, for SLE.

\section{Materials and methods}

Sample collection. Retrospective methods were adopted. A total of 194 patients with SLE who were admitted to the Department of Rheumatology at Yantaishan Hospital of Yantai (Yantai, China) from January 2012 to December 2017 were selected as SLE group. The average age was 40.82 \pm 13.46 years, including 23 males and 171 females. All cases were diagnosed according to the revised standards of the American Rheumatism Association (12). A total of 106 patients with non-SLE rheumatism were selected as disease control group, with an average age of $51.27 \pm 11.42$ years, including 18 males and 88 females. In the same period, 120 healthy subjects were selected as healthy control group with average age of 40.28 \pm 10.85 years, including 20 males and 100 females. Patients during pregnancy, lactating, suffering from other immune disease, or having incomplete clinical information were excluded. The heart, liver and kidney functions of all subjects enrolled were normal. The study was approved by the Ethics Committee of Yantaishan Hospital of Yantai. Signed informed consents were obtained from the patients or the guardians.

Results showed that there was no significant difference in age, sex, marriage and childbirth status between the three groups $(\mathrm{p}>0.05)$. The average red blood cell volume, distribution width of red blood cells, platelets, Hcy level, total cholesterol, and urine protein were significantly different $(p<0.001)$. General information is shown in Table I.
Reagents and equipment. ANA and anti-ds-DNA antibody kits were purchased from Trinity Biotech, Inc. (Jamestown, NY, USA); Microplate reader was purchased from Bio-Rad Laboratories, Inc. (Hercules, CA, USA); complement C3 and C4 kits were purchased from Beckman Coulter, Inc. (Brea, CA, USA); Hitachi automatic biochemical analyzer was purchased from Hitachi, Ltd. (Tokyo, Japan).

Detection methods. All subjects gave fasting venous blood ( $4 \mathrm{ml}$ ) and serum was centrifuged at 2,080 $\mathrm{x}$ g for $8 \mathrm{~min}$ at $4^{\circ} \mathrm{C}$. ANA and anti-ds-DNA antibody were determined by ELISA, and velocity nephelometry was used to determine complement C3 and C4. All test items were operated strictly in accordance with the manufacturer's instructions.

Interpretation of the results. The OD value of ANA and anti-ds-DNA antibody measured by a microplate reader was determined by the formula: OD value of sample/(mean OD of standard solution $\mathrm{x}$ correction factor); $\geq 1.1$ was positive, and $\leq 0.9$ was negative (13). The number of positive cases of complement C3 and C4 was determined based on the ROC curve.

Statistical analysis. SPSS 16.0 software was used for statistical analysis (Shanghai Kabei Information Technology Co., Ltd., Shanghai, China). Chi-square test was used for enumeration data and t-test was used for measurement data. One-way ANOVA was used for comparison among groups and SNK-q test was used as a post-hoc test for group analysis. ROC curves were used to analyze the diagnostic value of complement $\mathrm{C} 3$ and $\mathrm{C} 4$. $\mathrm{P}<0.05$ was considered to indicate a statistically significant difference. 
Table II. Comparison of the positive rate of autoantibody detection in SLE and disease control groups (\%).

\begin{tabular}{lccc}
\hline Group & $\begin{array}{c}\text { No. of } \\
\text { cases }\end{array}$ & ANA & $\begin{array}{c}\text { Anti-ds-DNA } \\
\text { antibody }\end{array}$ \\
\hline SLE group & 194 & $178(91.75)^{\mathrm{a}}$ & $130(67.01)^{\mathrm{a}}$ \\
Disease control group & 106 & $46(43.40)^{\mathrm{a}, \mathrm{b}}$ & $4(3.77)^{\mathrm{a}, \mathrm{b}}$ \\
Control group & 120 & $0(0)$ & $0(0)$ \\
$\chi^{2}$ & & 52.34 & 110.90 \\
P-value & & $<0.001$ & $<0.001$ \\
\hline
\end{tabular}

${ }^{\mathrm{a}} \mathrm{P}<0.05$, compared with control group; ${ }^{\mathrm{b}} \mathrm{p}<0.05$, compared with SLE group. SLE, systemic lupus erythematosus; ANA, antinuclear antibody; ds-DNA, double-stranded DNA.

Table III. Diagnostic sensitivity and specificity of ANA and anti-ds-DNA antibody for SLE (\%).

$$
\text { No. of }
$$

Antibody positive cases Sensitivity Specificity

\begin{tabular}{llll}
\hline ANA & 178 & 91.75 & 79.65 \\
Anti-ds-DNA & 130 & 67.01 & 98.23 \\
\hline
\end{tabular}

ANA, antinuclear antibody; ds-DNA, double-stranded DNA; SLE, systemic lupus erythematosus.

Table IV. Complement test results (g/l).

\begin{tabular}{lccc}
\hline Group & $\begin{array}{c}\text { No. of } \\
\text { cases }\end{array}$ & C3 & C4 \\
\hline SLE group & 194 & $0.58 \pm 0.24^{\mathrm{a}}$ & $0.19 \pm 0.08^{\mathrm{a}}$ \\
Disease control group & 106 & $0.64 \pm 0.23^{\mathrm{a}, \mathrm{b}}$ & $0.23 \pm 0.04^{\mathrm{a}, \mathrm{b}}$ \\
Control group & 120 & $0.97 \pm 0.15$ & $0.29 \pm 0.11$ \\
F & & 128.30 & 54.39 \\
P-value & & $<0.001$ & $<0.001$ \\
\hline
\end{tabular}

${ }^{\mathrm{a}} \mathrm{P}<0.001$, compared with control group; ${ }^{\mathrm{b}} \mathrm{p}<0.05$, compared with SLE group. SLE, systemic lupus erythematosus.

\section{Results}

Positive rate of autoantibody detection in SLE and disease control groups. The positive rates of ANA and anti-ds-DNA antibody in SLE group were 91.75 and $67.01 \%$, respectively. The positive rates of ANA and anti-ds-DNA antibody in disease control group were 43.40 and $3.77 \%$, respectively. The positive rates in the disease control and SLE groups were higher than that in the control group, and the differences were statistically significant $(\mathrm{p}<0.05)$. The difference between the positive rates in the disease control and SLE group was statistically significant $(\mathrm{p}<0.05)$. The sensitivity and specificity
Table V. Diagnostic sensitivity and specificity of complement C3 and C4 for SLE (\%).

\begin{tabular}{lccc}
\hline Complement & $\begin{array}{c}\text { No. of } \\
\text { positive cases }\end{array}$ & Sensitivity & Specificity \\
\hline C3 & 169 & 87.11 & 82.74 \\
C4 & 172 & 88.66 & 77.43 \\
C3+C4 & 180 & 92.78 & 79.20 \\
\hline
\end{tabular}

SLE, systemic lupus erythematosus.

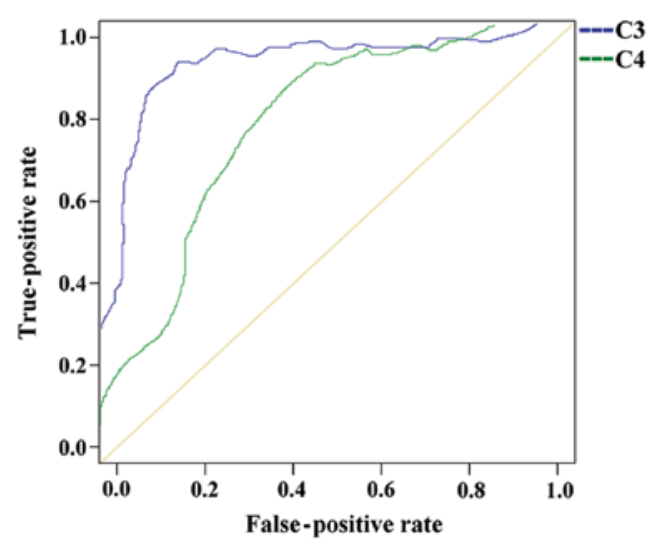

Figure 1. ROC curve analysis of the diagnosis of SLE by complement C3 and $\mathrm{C} 4$.

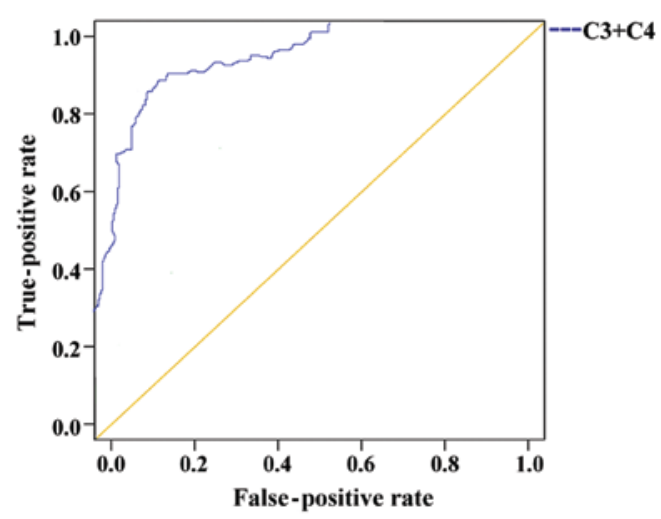

Figure 2. Diagnostic value of the combined use of complement C3 and C4 in SLE. The ROC curve analysis of the diagnosis of SLE by combination of $\mathrm{C} 3$ and $\mathrm{C} 4$ is shown.

of ANA in the diagnosis of SLE were $91.75 \%(178 / 194)$ and $79.65 \%$ (180/226), respectively. The sensitivity and specificity of anti-ds-DNA antibody in the diagnosis of SLE were $67.01 \%$ (130/194), 98.23\% (222/226) (Tables II and III).

Complement test results. The expression levels of C3 and C4 in SLE and disease control groups were lower than those in control group, and the differences were statistically significant $(\mathrm{p}<0.001)$. The expression levels of $\mathrm{C} 3$ and $\mathrm{C} 4$ in the disease control group were significantly different from those in the SLE group $(\mathrm{p}<0.05)$ (Table IV). 
Table VI. Combined sensitivity in SLE diagnosis (\%).

\begin{tabular}{|c|c|c|c|c|}
\hline Item & $\mathrm{n}$ & $\begin{array}{c}\text { No. of } \\
\text { positive } \\
\text { cases }\end{array}$ & Sensitivity & Specificity \\
\hline $\begin{array}{l}\text { ANA+anti-ds-DNA } \\
\text { antibody }\end{array}$ & 420 & 185 & 95.36 & 96.90 \\
\hline $\mathrm{C} 3+\mathrm{C} 4$ & 420 & 180 & 92.78 & 79.20 \\
\hline $\mathrm{ANA}+\mathrm{ds}-\mathrm{DNA}+\mathrm{C} 3+\mathrm{C} 4$ & 420 & 189 & 97.42 & 80.97 \\
\hline
\end{tabular}

SLE, systemic lupus erythematosus; ANA, antinuclear antibody; ds-DNA, double-stranded DNA.

Comparison of the sensitivity and specificity of complement $C 3$ and C4 in SLE diagnosis. The ROC curve analysis of the diagnosis of SLE with complement C3 showed that the AUC for the diagnosis of SLE with C3 was 0.903, the progressive $95 \%$ confidence interval was $0.869-0.937$, the cut-off value was 0.663 , the SLE group positive case number was 169 , the number of positive cases in the disease control group was 39, the sensitivity was $87.11 \%$ and the specificity was $82.74 \%$.

The ROC curve analysis of the diagnosis of SLE with complement $\mathrm{C} 4$ showed that the AUC was 0.763 , the progressive $95 \%$ confidence interval was $0.705-0.820$, the cut-off value was 0.434 , the SLE group included 172 positive cases, the number of positive cases in the disease control group was 51 , the sensitivity was $88.66 \%$ and the specificity was $77.43 \%$.

The ROC curve analysis of the diagnosis of SLE by combination of $\mathrm{C} 3$ and $\mathrm{C} 4$ showed that the AUC of the combined diagnosis of SLE was 0.931 , the progressive $95 \%$ confidence interval was $0.904-0.958$, the cut-off value was 0.727 , the SLE group included 180 positive cases, the number of positive cases in the disease control group was 47, the sensitivity was $92.78 \%$, and the specificity was $79.20 \%$ (Figs. 1 and 2, and Table V).

Comparison of the sensitivity of the combined application in SLE diagnosis. The sensitivity and specificity of ANA and ds-DNA in the diagnosis of SLE were 95.36\% (185/194) and $96.90 \%(219 / 226)$, respectively; of C3 and C4 were $92.78 \%(180 / 194)$ and $79.20 \%(179 / 226)$; and of all the four factors were $97.42 \%(189 / 194)$ and $80.97 \%$ (183/226), respectively (Table VI).

\section{Discussion}

Pathogenesis and causes of SLE are complex. Many factors such as environment, heredity and estrogen can stimulate the body's immune regulation, promote the deposition of antigens, antibodies and complements, and induce local or systemic multi-organ and -tissue injuries (14). The immunological abnormalities of SLE are mainly manifested by the presence of multiple autoantibodies represented by ANA in serum (15). Currently, the main cause of SLE tissue damage is immune complex allergy, which can activate allergic reactions through classic and alternative pathways while consuming complement (16). ANA, anti-ds-DNA antibody, and complement C3 and $\mathrm{C} 4$ associated with SLE are important indicators for the diagnosis of SLE. In this study, 194 patients with SLE had a sensitivity of $91.75 \%$ and a specificity of $79.65 \%$ in detecting serum ANA. Kumar and Bhatia (17) have reported that the diagnostic sensitivity and specificity of ANA for SLE are 95 and $65 \%$, respectively, similar to our results. This suggests that the detection of ANAs lacks specificity and ANAs may also be present in other connective tissue diseases besides SLE. According to the results presented in Table II, the positive rate of ANA in the serum of 106 patients of the disease control group was $43.40 \%$. Due to the deficiency of specificity of ANA in the diagnosis of SLE, ANA may also be present in other connective tissue diseases; negative ANA does not completely indicate that there is no SLE, which is consistent with literature (18).

According to the results, 16 cases of SLE patients were pathologically confirmed with negative serum ANA. These may belong to a subcategory of SLE, in which case the common clinical features of photosensitivity, and clinical features of arthritis, kidney damage are rare (19). Therefore, the detection of ANA in the diagnosis of SLE is only of screening value. Only when the ANA is positive and clinical features of SLE are present the detection of ANA can be used as a definite diagnosis of SLE. This study showed that the sensitivity and specificity of the detection of anti-ds-DNA antibody in SLE were 67.01 and $98.23 \%$, respectively. The sensitivity was poor, but the specificity was higher. Roggenbuck et al (20) have shown that anti-dsDNA antibody can be used as a marker for the diagnosis of SLE. This also confirms the high specificity of anti-ds-DNA antibody in our results. In addition, ds-DNA can become negative after the disease improves with treatment, so anti-ds-DNA antibody can provide the basis for monitoring treatment (21). The expression levels of C3 and C4 in SLE and disease control groups were lower than those in control group, and the differences were statistically significant ( $<<0.001)$. Liu et al (22) have reported that the decrease of the levels of complement C3 and C4 in the serum of SLE patients means that the patient has increased autoantibodies, which is the manifestation of immune activation, and it may also be complement-mediated cytotoxicity. This is consistent with our findings, therefore, the decrease of complement C3 and C4 levels in serum can be used as diagnosis standard of SLE. According to the results of the ROC curves, the sensitivity of C3 in the diagnosis of SLE was $87.11 \%$ and the specificity was $82.74 \%$; the sensitivity of complement $\mathrm{C} 4$ was $88.66 \%$ and the specificity was $77.43 \%$; and the sensitivity of the combination of C3 and C4 in the diagnosis of SLE was $92.78 \%$ and the specificity is $79.20 \%$. This shows that complement C3 and $\mathrm{C} 4$ are not very specific indicators of SLE, but they have a screening value in the diagnosis of SLE, and the sensitivity of combined diagnosis of SLE is improved. The sensitivity and specificity of ANA and anti-ds-DNA antibody in the diagnosis of SLE were 95.36 and $96.90 \%$, respectively; of C3 and C4 were 92.78 and $79.20 \%$, respectively; and of the combination of all four indicators were 97.42 and $80.97 \%$, respectively. The sensitivity of combined ANA and anti-ds-DNA antibody, the combined $\mathrm{C} 3$ and $\mathrm{C} 4$, and all four indicators in the diagnosis of SLE was higher than that of these antibodies alone, but the specificity of all four combined factors in the diagnosis of SLE was lower than that of anti-ds-DNA antibody. The sensitivity and specificity of autoantibody detection are different in different populations and disease activity levels. Therefore, 
it is not possible to diagnose the disease with only one or a single index. Joint detection can prove the indicators to play a complementary role.

In summary, ANA has the highest sensitivity in the diagnosis of SLE, but its specificity is the worst; anti-ds-DNA antibody has the lowest sensitivity for the diagnosis of SLE, but the highest specificity. Therefore, combining ANA, anti-ds-DNA antibody, complement $\mathrm{C} 3$ and $\mathrm{C} 4$ can be used for the diagnosis of SLE in order to reduce or even avoid the missed diagnosis caused by a single test, to provide a complementary and confirmatory effect, and to improve the positive diagnosis rate of SLE.

\section{Acknowledgements}

Not applicable.

\section{Funding}

No funding was received.

\section{Availability of data and materials}

The datasets used and/or analyzed during the present study are available from the corresponding author on reasonable request.

\section{Authors' contributions}

$\mathrm{CQ}$ and $\mathrm{JZ}$ drafted the manuscript. CQ, JZ and XZ were mainly devoted in collecting and interpreting the general data. JD and BS were responsible for ELISA. HL performed the velocity nephelometry. All authors read and approved the final manuscript.

\section{Ethics approval and consent to participate}

The study was approved by the Ethics Committee of Yantaishan Hospital of Yantai (Yantai, China). Signed informed consents were obtained from the patients or the guardians.

\section{Patient consent for publication}

Not applicable.

\section{Competing interests}

The authors declare that they have no competing interests.

\section{References}

1. Rönnblom L and Pascual V: The innate immune system in SLE: Type I interferons and dendritic cells. Lupus 17: 394-399, 2008.

2. Coluccia AM, Cirulli T, Neri P, Mangieri D, Colanardi MC, Gnoni A, Di Renzo N, Dammacco F, Tassone P, Ribatti D, et al: Validation of PDGFRbeta and c-Src tyrosine kinases as tumor/vessel targets in patients with multiple myeloma: Preclinical efficacy of the novel, orally available inhibitor dasatinib. Blood 112: 1346-1356, 2008.

3. Egner W: The use of laboratory tests in the diagnosis of SLE. J Clin Pathol 53: 424-432, 2000.
4. Su DL, Wang HJ, Ji XH, Li YY, Xuan HB, Heng C and Li YF: Mycophenolic acid inhibits SLE-associated cytokine expression and promotes apoptosis of peripheral blood mononuclear cells from patients with systemic lupus erythematosus. Acta Pharmacol Sin 27: 1051-1057, 2006.

5. Mackay M, Stanevsky A, Wang T, Aranow C, Li M, Koenig S, Ravetch JV and Diamond B: Selective dysregulation of the FcgammaIIB receptor on memory B cells in SLE. J Exp Med 203: 2157-2164, 2006.

6. Zhao P, Xu L, Wang P, Liang X, Qi J, Liu P, Guo C, Zhang L, $\mathrm{Ma} \mathrm{C}$ and Gao L: Increased expression of human T-cell immunoglobulin- and mucin-domain-containing molecule- 4 in peripheral blood mononuclear cells from patients with system lupus erythematosus. Cell Mol Immunol 7: 152-156, 2010.

7. Yu SL, Wong CK, Wong PTY, Chen DP, Szeto CC, Li EK and Tam LS: Down-regulated NOD2 by immunosuppressants in peripheral blood cells in patients with SLE reduces the muramyl dipeptide-induced IL-10 production. PLoS One 6: e23855, 2011.

8. Muratori P, Muratori L, Ferrari R, Cassani F, Bianchi G, Lenzi M, Rodrigo L, Linares A, Fuentes D and Bianchi FB: Characterization and clinical impact of antinuclear antibodies in primary biliary cirrhosis. Am J Gastroenterol 98: 431-437, 2003.

9. Xu XF, Zhang J, Cui L, Wang YH, Yue Y, Chi L, Bai J, Li HM and $\mathrm{Lu} \mathrm{XX:}$ : The value of different antibodies detection in diagnosis of rheumatism with uveitis. Zhonghua Yi Xue Za Zhi 97: 285-290, 2017 (In Chinese).

10. Song XY, Huang H, Liu YZ, Zhao YY, Li S and Xu ZJ: Coexistence of sarcoidosis and primary Sjögren syndrome: A clinical analysis and literature review. Zhonghua Nei Ke Za Zhi 56: 375-377, 2017 (In Chinese).

11. Buhl A, Metzger JH, Heegaard NH, von Landenberg P, Fleck M and Luppa PB: Novel biosensor-based analytic device for the detection of anti-double-stranded DNA antibodies. Clin Chem 53: 334-341, 2007.

12. Calano SJ, Shih PA, Liu CC, Kao AH, Navratil JS, Manzi S and Ahearn JM: Cell-bound complement activation products (CB-CAPs) as a source of lupus biomarkers. Adv Exp Med Biol 586: 381-390, 2006.

13. Hochberg MC: Updating the American College of Rheumatology revised criteria for the classification of systemic lupus erythematosus. Arthritis Rheum 40: 1725, 1997.

14. Liu Y, Jing H, Wang J, Zhang R, Zhang Y, Zhang Y, Xu Q, $\mathrm{Yu} \mathrm{X}$ and Xue C: Micronutrients decrease incidence of common infections in type 2 diabetic outpatients. Asia Pac J Clin Nutr 20: 375-382, 2011.

15. Salaman MR and Isenberg DA: The immunological personality of close relatives of SLE patients. Lupus 26: 1513-1516, 2017.

16. Liu CC, Manzi S, Kao AH, Navratil JS and Ahearn JM: Cell-bound complement biomarkers for SLE: From benchtop to bedside. Rheum Dis Clin North Am 36: 161-172, 2010.

17. Kumar Y and Bhatia A: Detection of antinuclear antibodies in SLE. Methods Mol Biol 1134: 37-45, 2014.

18. Kasitanon N, Magder LS and Petri M: Predictors of survival in systemic lupus erythematosus. Medicine (Baltimore) 85: 147-156, 2006.

19. Li LH, Pan HF, Li WX, Li XP, Xu JH and Ye DQ: Study on clinical features and complications with systemic lupus erythematosus (SLE) activity in Chinese Han population. Clin Rheumatol 28: 1301-1307, 2009.

20. Roggenbuck D, Reinhold D, Hiemann R, Anderer U and Conrad K: Standardized detection of anti-ds DNA antibodies by indirect immunofluorescence - a new age for confirmatory tests in SLE diagnostics. Clin Chim Acta 412: 2011-2012, 2011.

21. Waris $\mathrm{G}$ and Alam K: Immunogenicity of superoxide radical modified-DNA: Studies on induced antibodies and SLE anti-DNA autoantibodies. Life Sci 75: 2633-2642, 2004.

22. Liu H, Yang LH, Yin G and Xie QB: Correlation of thyroid autoantibodies, system lupus erythematosus immunologic indicators and disease activity in SLE with HT. Sichuan Da Xue Xue Bao Yi Xue Ban 49: 179-182, 2018 (In Chinese).

This work is licensed under a Creative Commons Attribution-NonCommercial-NoDerivatives 4.0 International (CC BY-NC-ND 4.0) License. 